\title{
A ABORDAGEM BIOGRÁFICA DAS MIGRAÇÕES TRANSNACIONAIS: OS CASOS HAITIANO E SENEGALÊS NO BRASIL
}

- MARIA DO CARMO DOS SANTOS GONÇALVES

Pontifícia Universidade Católica do Rio Grande do Sul

\section{LUCAS CÉ SANGALLI}

Centro de Métodos em Ciências Sociais, Universidade de Göttingen

RESUMO O presente artigo apresenta uma contribuição ao debate sobre as migrações transnacionais, a partir da abordagem biográfica. Baseado na sociologia do conhecimento (Peter Berger e Thomas Luckmann, 1991) e na abordagem biográfica de matriz alemã (Fritz Schütze, 1983 e Gabriele Rosenthal, 2014), são apresentadas duas reconstruções de casos biográficos: o primeiro é o de um migrante do Haiti, que passou por Equador, Peru, Brasil, Estados Unidos e Canadá com sua família, e o segundo, o de um migrante do Senegal que, ao sair de seu país, já tinha o Brasil como destino principal.

Palavras-chave: Migração. Biografia. Narrativa biográfica. Haiti. Senegal.

\section{ABSTRACT THE BIOGRAPHICAL APPROACH TO TRANSNATIONAL MIGRATIONS: THE HAITIAN AND THE SENEGALESE CASES IN BRAZIL}

This article uses the biographical approach to contribute to the debate on transnational migrations. Based on the Sociology of knowledge (Peter Berger and Thomas Luckmann, 1991) and the German biographical approach (Fritz Schütze, 1983, and Gabriele Rosenthal, 2014), the article presents two biographical case reconstructions: the first one reconstructs the life of a migrant from Haiti that lived in Ecuador, Peru, Brazil, the United States, and Canada with his family; the second one reconstructs the life of a migrant from Senegal, who left Senegal with the idea of moving to Brazil.

Keywords: Migration. Biography. Biographical narrative. Haiti. Senegal. 


\section{RESUMEN EL ENFOQUE BIOGRÁFICO DE LAS MIGRACIONES TRANSNACIONALES: LOS CASOS HAITIANO Y SENEGALÉS EN BRASIL}

El presente artículo presenta una contribución al debate sobre las migraciones transnacionales a partir del enfoque biográfico. Basado en la sociología del conocimiento (Peter Berger y Thomas Luckmann, 1991) y en el enfoque biográfico alemán (Fritz Schütze, 1983, y Gabriele Rosenthal, 2014), se presentan las reconstrucciones de dos casos biográficos: el primero se refiere a un migrante de Haiti, que pasó por Ecuador, Perú, Brasil, Estados Unidos y Canadá con su familia; y el segundo a un migrante de Senegal, que al salir de su país ya tenía a Brasil como destino final.

Palabras clave: Migración. Biografía. Narrativa biográfica. Haití. Senegal.

\section{Introdução}

Os recentes fluxos migratórios para o Brasil têm suscitado uma série de debates, dentre os quais emerge o tema da transnacionalização das migrações. Segundo Cogo e Badet (2013, p. 48), a expressão transnacionalismo referese a "processos mediante os quais os imigrantes constroem relações sociais que conectam as sociedades de origem e destino para além das fronteiras nacionais". Nessa perspectiva, o "transmigrante" seria aquele que "mantém relações familiares, sociais, econômicas e políticas com diferentes espaços e lugares" (COGO; BADET, 2013, p. 48).

Considerando a abordagem biográfica, o presente trabalho analisa aspectos do fenômeno da transnacionalização dos fluxos migratórios para o Brasil, a partir de duas biografias de migrantes vindos do Haiti e do Senegal. Avaliando que o campo da pesquisa biográfica se caracteriza pela diversidade de metodologias, indicamos os principais pressupostos teóricometodológicos utilizados e, posteriormente, alguns pontos de análise sobre as migrações transnacionais, ancorados nas reconstruções de casos biográficos referentes ao caso de um imigrante que veio do Haiti e atualmente vive no Canadá e de um imigrante que veio do Senegal e vive no Brasil.

A pesquisa foi realizada com base nos pressupostos de uma pesquisa social interpretativa (WILSON, 1980). No que diz respeito ao levantamento dos dados, tomamos como referência o princípio da abertura (HOFFMANN-RIEM, 1980), e, em relação à amostra, utilizamos a proposta da grounded theory de Glaser e Strauss (1967). Disto decorre o entendimento de que a amostra de entrevistados foi ajustada ao longo da pesquisa e de acordo com os resultados que emergiram durante o trabalho de campo (theoretical sampling). O resultado dessa lógica circular entre a construção e a análise dos dados, leva em consideração alterações na pergunta inicial e na temática, permitindo a descoberta do novo (GLASER; STRAUSS, 1967). Com isso, conseguimos estudar o processo migratório, em suas dimensões diacrônica e sincrônica, não ficando restritos a uma descrição dele 
no presente. Isso está relacionado ao nosso posicionamento com Rosenthal (2012), que identifica as limitações de uma pesquisa a-histórica dos fenômenos sociais, considerando as implicações políticas decorrentes disso, principalmente no campo de estudo das migrações.

\section{A abordagem biográfica}

Nas ciências sociais brasileiras, de acordo com Santos et al (2014), as variantes da pesquisa qualitativa que investigam relatos de vida são utilizadas desde 1940.' A abordagem biográfica aqui proposta tem um entendimento do conceito de biografia que não está restrito ao nivel individual. Toda biografia é compreendida como um construto social (ROSENTHAL, 2014), isto é, resultado da socialização do indivíduo em interação com outros indivíduos na sociedade. Indivíduos nascem e são socializados em um contexto social maior que "autoriza ou nega" certas manifestações biográficas (ELIAS, 1994), as quais são essenciais à compreensão das motivações para um migrante deixar seu país e que podem ou não estar atreladas a fatores latentes da biografia do indivíduo. Isto é, sua compreensão exige um método capaz de respeitar o sistema de relevância do indivíduo para evitar que o pesquisador meramente projete suas hipóteses explicativas sobre o fenômeno em análise. Padrões gerais da socialização do indivíduo são ressaltados para informar o pesquisador a respeito dos processos que ocorrem no nivel da sociedade. Parte-se de um nível individual da biografia do migrante para ter-se acesso a um nivel da motivação social representada no

1 Para uma revisão da literatura sobre o uso de relatos de histórias de vida na sociologia brasileira, ver Santos et al (2014) e Cunha e Alheit (2018). Estes últimos escrevem sobre a abordagem biográfica no Brasil, mas deixam uma lacuna em relação aos estudos desenvolvidos no âmbito da Pontifícia Universidade Católica do Rio Grande do Sul, em parceria com a Universidade de Göttingen, Alemanha. processo migratório. Mais que isso, a análise não está limitada à perspectiva epistemológica dual, mas procura compreender influências constitutivas do nivel individual sobre o social e vice-versa.

A pesquisa biográfica trabalha sistematicamente como uma teoria interacionista da socialização que busca apreender a relação constitutiva entre as definições construídas pelo próprio indivíduo e as que partem do outro, ou, dito de forma geral, a relação constitutiva entre geral e particular e os efeitos dessa relação. (ROSENTHAL, 2014, p. 222)

O método de reconstrução de caso biográfico, como sistematizado por Gabriele Rosenthal (2014), consiste na combinação da análise de textos de Fritz Schütze (1983; 2007a; 2007b), da hermenêutica estrutural de Ulrich Oevermann et al (1979) e da análise de campo temático de Aaron Gurwitsch (1974). A reconstrução do processo de gênese de determinado fenômeno na biografia individual diferencia-se de um estudo de caso, na medida em que a reconstrução de um caso biográfico identifica e explica o desenvolvimento de determinado fenômeno, não se limitando a sua descrição (ROSENTHAL, 2014).

Com isso, a reconstrução de caso biográfico guarda uma dimensão essencialmente empírica, uma vez que as proposições teóricas estão fundamentadas na apresentação do fenômeno empírico. Nesse sentido, o pesquisador deve, na medida do possivel, ir a campo sem hipóteses prévias de pesquisa em mente. Essa noção está presente no princípio da abertura de uma pesquisa social interpretativa (HOFFMANN-RIEM, 1980), que alude à ideia de que o pesquisador não vai a campo com hipóteses determinadas a priori, simplesmente para buscar respaldo empírico para pressupostos teóricos. Ao contrário, a pergunta de pesquisa é realizada de forma aberta e é detalhada ao longo 
do trabalho de campo. Com isso, as etapas de construção dos dados, determinação da amostra e análise dos dados influenciamse mutuamente, em uma lógica circular, que pode indicar a redefinição das questões de pesquisa. Esse tipo de investigação procura fazer, ao final da análise, generalizações teóricas fundamentadas na realidade empírica, daí o nome de teoria fundamentada (grounded theory) (GLASER; STRAUSS, 1967). Em contraste com teorias lógico-dedutivas, a teoria fundamentada é adequada à formulação de teoria na sociologia, porque não está separada do processo pelo qual é criada (GLASER; STRAUSS, 1967).

A construção dos dados corresponde à prática de uma entrevista narrativa, na qual é feita uma pergunta aberta a respeito da história de vida dos entrevistados e de sua família. A análise dos dados biográficos ocorre em fases concomitantes, quais sejam: a) a análise sequencial dos dados biográficos; b) a análise textual e de campo temático (reconstrução da vida narrada); c) a reconstrução da vida vivenciada; d) a comparação entre vida vivenciada (passado - dimensão diacrônica) e vida narrada (presente - dimensão sincrônica); e) a construção de um tipo.

O caso haitiano foi reconstruído com base em duas entrevistas narrativas e o caso senegalês foi feito com base em uma entrevista narrativa. ${ }^{2}$ Essas entrevistas não tiveram constrangimento de tempo e foram realizadas em locais escolhidos pelos entrevistados. No caso haitiano, elas aconteceram na casa da família do entrevistado e, no caso senegalês, a entrevista foi feita no ambiente de uma organização da sociedade civil frequentada pelo entrevistado.

2 É importante referir que o caso do imigrante haitiano utilizou como base a dissertação de mestrado de Lucas Cé Sangalli (2015), onde o caso está apresentado com mais detalhes. Para mais, ver: Cé Sangalli (2015).
Apontamentos sobre migrações transnacionais a partir de reconstruções de casos
biográficos

Trazendo presente os pressupostos teóricos de uma pesquisa social interpretativa, utilizamos o método de entrevista narrativa biográfica (SCHÜTZE, 1983; ROSENTHAL, 2014) para estabelecer a reconstrução de dois casos biográficos, um referente à biografia de um imigrante haitiano e outro senegalês. ${ }^{3}$

A questão transnacional dos processos migratórios leva em consideração a crescente complexidade da sociedade contemporânea, dinâmicas de movimentação de indivíduos, ideias, valores e normas, e distintas construções de cotidiano, a partir dos quais sentimentos de pertencimento são estabelecidos (GLICK SCHILLER et al, 1995; PRIES, 2000).

[...] A migração transnacional é o processo pelo qual imigrantes forjam e sustentam relações sociais simultaneamente multi-referenciadas, que conectam suas sociedades de origem com a de estabelecimento. [...] enfatizam-se as formas correntes e contínuas pelas quais os imigrantes contemporâneos constroem e reconstituem seu acoplamento simultâneo em mais de uma sociedade. (GLICK SCHILLER et al, 1995, p. 48, tradução nossa)

Nessa perspectiva, os estudos migratórios não enfatizam o estado-nação, mas a construção de um espaço social na interseção dos espaços global e local (APITZSCH; SIOUTI, 2007). ${ }^{4}$

3 É importante ressaltar que o caso senegalês ainda está em processo de reconstrução, sendo parte da amostra de entrevistas utilizada por Maria do Carmo dos Santos Gonçalves, em sua tese de doutorado sobre religião e imigração senegalesa, na região sul do Brasil.

4 Glick Schiller et al (1995, p. 48) colocam que: “Transmigrantes são imigrantes cuja vida cotidiana depende de interconexões múltiplas e constantes através de fronteiras internacionais e cujas identidades públicas são configuradas em relação a mais de um estado-nação. [...] eles se estabelecem e são incorporados pela economia e pelas instituições políticas, localidades e padrões da vida cotidiana do país no qual residem. 
O Caso Alain: profecia religiosa e sentido em um processo

\section{migratório que tem o Haiti como destino final latente}

A agenda de pesquisa sobre a migração de haitianos e da diáspora haitiana passou a fazer parte das ciências sociais brasileiras, principalmente a partir do abalo sísmico que atingiu a capital haitiana e arredores, em janeiro de 2010. Estudos in loco já vinham sendo desenvolvidos por pesquisadores do Museu Nacional/UFRJ, em parceria com instituições do Haiti (NEIBURG, 2014; DALMASO, 2009; SILVA, 2010; BAPTISTA, 2012). A aproximação recente entre Brasil e Haiti ocorreu no contexto dos esforços da Missão das Nações Unidas para a Estabilização do Haiti (Minustah), estabelecida pelo Conselho de Segurança das Nações Unidas, na Resolução 1542, em 2004, e encerrada no ano de 2017. A aproximação entre Brasil e Haiti refletiu-se no aumento do fluxo de migrantes haitianos para o Brasil, principalmente a partir de 2010 (PATARRA, 2012; MORAES et al, 2013; SILVA, 2013). ${ }^{5} \mathrm{Em}$ 2011, houve o registro de imigrantes haitianos na região de Mato Grosso do Sul (PIMENTEL; COTINGUIBA, 2014). As principais rotas de entrada no território brasileiro foram a tríplice fronteira nas regiões de Tabatinga ( $A M)$, entre Brasil, Peru e Colômbia, e a região de Assis Brasil ( $A C)$, entre Brasil, Peru e Bolívia (PATARRA, 2012; PIMENTEL; COTINGUIBA, 2014; SILVA, 2014).

Apesar de avanços significativos na compreensão desse fenômeno social, as pesquisas sobre migração haitiana no Brasil têm mantido

No entanto, ao mesmo tempo, estão envolvidos com outro lugar, no sentido de que mantêm conexões, constroem instituições, conduzem transações e influenciam eventos locais e nacionais nos países dos quais emigraram" (tradução nossa).

5 Em relação ao número de haitianos vivendo no Brasil, a despeito da dificuldade para o registro desses deslocamentos, Milesi (2016), com base em dados fornecidos pela Polícia Federal, aponta que mais de 73.000 haitianos viviam no Brasil em 2016. seu foco no levantamento de dados estatísticos e demográficos (FERNANDES et al, 2013; ZAMBERLAN et al, 2014; FERNANDES; CASTRO, 2014; CARRERA, 2014; METZNER, 2014), na descrição de rotas (SILVA, 2014; VÁSQUEZ; BUSSE; IZAGUIRRE, 2014) e na condição jurídico-legal dos haitianos no Brasil (GODOY, 2011; FERNANDES et al, 2013; REDIN; BARBOSA, 2014). Como enfatiza Cogo (2013), são poucos os esforços no sentido de questionar categorias já difundidas no estudo das migrações. Nesse sentido, o caso apresentado a seguir sugere o uso de novas abordagens, como a biográfica, para aprofundar a compreensão desse fenômeno.

Alain ${ }^{6}$ nasceu em uma família de fé evangélica, bastante atuante na comunidade em uma região rural do Haiti. Grande parte da população haitiana é praticante do vodu, de modo que Alain nasce inscrito em uma "ilha" evangélica, em um universo mágico influenciado majoritariamente por crenças vodus. ${ }^{7}$ Durante sua infância, Alain sofreu um acidente durante uma brincadeira. Seus pais levaram-no ao médico, que indicou a morte iminente do menino, segundo o relato de Alain. Desolados com a sentença médica, ele e seus pais foram para casa, "aguardando por sua morte", como relata. No entanto, um contraponto à perspectiva médica foi "revelado" a sua mãe por uma mulher "tocada por Deus", que deu para ela uma profecia a respeito da vida de Alain, que o situava como alguém di-

60 nome dos entrevistados, seus familiares e sua cidade de nascimento foram modificados para garantir que não sejam identificados.

7 Apesar da aparente baixa representatividade que o estudo de um haitiano evangélico parece ter perante uma população majoritariamente vodu, dados levantados pelo CIBAI (ZAMBERLAN et al, 2014) indicam que aproximadamente $60 \%$ dos imigrantes haitianos entrevistados no sul do Brasil são evangélicos, ao passo que $39,3 \%$ são católicos e $1,2 \%$ se declara praticante de outra religião. Além disso, a difusão de práticas evangélicas tem ganhado força não somente nos estudos sobre o Haiti, historicamente preocupados com rituais e práticas vodu, mas também com o impacto do pentecostalismo na diáspora haitiana. (BRODWIN, 2003) 
ferente dos outros, destinado a grandes feitos, como o de ser um grande político da nação haitiana. A profecia dizia que Alain seria um explorador, que abriria caminhos pelos quais sua família e outras pessoas seguiriam posteriormente. A ideia da profecia é importante na exposição da biografia de Alain porque atua como um elemento que dá coesão e sentido à forma como ele apresenta sua vida. Além disso, evidencia a centralidade da compreensão mágico-religiosa na conferência de significado à vida de Alain.

$O$ acidente que ocorre durante sua infância e a profecia sobre sua vida recebida por sua mãe parecem ser determinantes fortes associadas à primeira movimentação biograficamente relevante na vida de Alain: a saída do interior do Haiti em direção à região metropolitana da capital. A história a respeito da profecia sobre sua vida foi-lhe repassada por sua mãe, o que pode servir como um indicador da força que um relato transmitido por um familiar pode ter sobre a constituição do sentido para Alain, ao longo de sua trajetória (RIEMANN; SCHÜTZE, 1991).

Em conjunto com a formação de mundo vinculada ao contexto religioso e à percepção sociocultural que seus pais perpetuam, Alain percebe na saída do país uma alternativa ao seu contexto de nascimento, desde muito cedo, quando seu irmão foi morar na França com o irmão de sua mãe, aos 14 anos. As condições que possibilitam a saída do irmão do núcleo familiar estão atreladas às motivações dos diversos irmãos da mãe de Alain, que também deixaram o país na mesma época, o que se poderia chamar de uma "cultura de diáspora" relacionada a figurações sociais específicas a esse período da história do Haiti, quando diversos indivíduos e famílias foram viver no exterior (STEPICK, 1998; LINSTROTH et al, 2009).

O primeiro movimento executado por Alain - a ida diária até a região metropolitana da ca- pital para estudar durante sua adolescência - é central à compreensão adequada de sua saída do Haiti. Esse movimento reforça conteúdos da profecia a respeito de sua vida, de modo que o situa de fato como um explorador em relação àqueles pertencentes às figurações atreladas ao seu contexto de nascimento. A importância do reforço dessa percepção é o papel determinante que a profecia sobre sua vida terá na leitura que Alain faz de sua saída do Haiti.

No momento em que ele decide deixar o Haiti, já se havia configurado socialmente como um explorador, como aquele que abriria caminhos pelos quais sua família seguiria. Apesar desta compreensão estar atrelada a uma dimensão intangível de sua vida, sua relação com Deus, as possibilidades de perceber a saída de seu país como uma alternativa já estavam presentes nessa "revelação". Aliado a isso, a saída de parentes do país (e a presença de familiares em Quito) e o ensejo de seus pais para que procurasse alternativas desde cedo atuam em conjunto com as condições de vida no Haiti, após o terremoto, como determinantes da segunda movimentação em sua trajetória.

O terceiro movimento na vida de Alain - sua saída de Quito em direção à tríplice-fronteira entre Peru, Brasil e Bolívia - remete a elementos presentes nas movimentações anteriores, mas se vincula, principalmente, à vontade de seu núcleo familiar. Os pais de Alain, insatisfeitos com a vida que seus filhos levavam na capital do Equador, sugerem e, posteriormente, exigem essa mudança. Novamente, Alain responsabiliza-se pela movimentação, apesar de ter vivido por mais de um ano no Equador e não ter saído do país, o que pode ser visto como um indicador da centralidade da presença de seus pais na ocorrência dessa mudança. Em conjunto com os projetos que seus pais tinham para seus filhos, deve-se considerar ainda as figurações sociais equatorianas, de onde 
emergem a imposição a Alain e seus familiares de práticas cotidianas que enfatizam a cor de sua pele.

Em consonância com as influências sobre a decisão de Alain de sair de Quito, pode-se colocar o percurso percorrido por seu tio paterno, fundamental não apenas ao movimento de saída de Alain em direção ao Equador, mas à decisão de Alain ir até a fronteira com o Brasil. Em Iñapari (Peru), Alain situa-se em uma região de fronteira, fortemente caracterizada pelo fluxo de bens e pessoas. É importante atentar para a existência fática dos estados nacionais nesse ponto, uma vez que Alain não entra no Brasil porque precisa de uma autorização legal da Polícia Federal brasileira. Com isso, vive em uma zona juridicamente indeterminada, em cidades aquém dos controles aduaneiros, ou seja, em um espaço de sobreposições (GLICK SCHILLER et al, 1995; PRIES, 2000) das cidades de Iñapari (Peru), Bolpebra (Bolívia) e Assis Brasil (Brasil).

As relações cotidianas desenvolvidas sobre esse território não são, no entanto, indeterminadas (SANTOS, 2011). Pelo contrário, os referenciais que Alain estabelece em relação à região são claros em sua narrativa. Do mesmo modo, as relações sociais com habitantes da região são retomadas e servem como ponto de retorno para Alain, em outro momento de sua biografia. Com isso, percebe-se que, a despeito das indefinições jurídicas, há a formação clara de um espaço social transnacional (PRIES, 2000), atrelado à região, em relação ao qual Alain orienta suas movimentações.

$\mathrm{Na}$ fronteira, Alain entra em contato com nacionais de distintos países, bem como com agentes especializados na travessia da fronteira. É a primeira vez em seu processo de movimentação que ele está exposto à influência de indivíduos que fazem do tráfico de pessoas e do atravessamento da fronteira, uma profissão juridicamente informal, mas com respal- do prático. A zona de fronteira é caracterizada ainda pelas redes de agentes multinacionais que detêm informação a respeito de questões jurídicas e práticas da travessia desses territórios. Nesse sentido, a decisão de Alain de entrar no Brasil é feita com base em uma série de informações específicas que adquire ao vivenciar o cotidiano na zona de fronteira. Com o conhecimento adquirido na região e pelo acionamento dos agentes adequados, Alain executa a movimentação que passa por Brasileia (Acre) e termina em Rio Branco.

A quarta movimentação da vida de Alain, a saída do norte em direção ao sul do Brasil, está atrelada a diversos fatores. Dentre eles, a insatisfação de seus pais com a cidade de Rio Branco. Mais uma vez, a chegada dos pais para conviver com Alain e dos irmãos atua como desencadeador de uma movimentação em sua vida. Seu relacionamento com Ana em Rio Branco e seu emprego na pizzaria dela pareciam ser bastante satisfatórios para Alain, dadas as condições nas quais vivera no Equador e no Peru. Entretanto, a chegada dos familiares coloca um novo conflito, uma vez que Alain acreditava que seus pais não aceitariam a gravidez de Ana. A chegada no sul acontece com um conflito latente, o fato de não ter revelado aos seus pais a gravidez de Ana. Alain explicita que, quando saiu de Rio Branco, sua intenção era acompanhar a família até o sul, ajudar em seu estabelecimento e retornar ao norte, para viver com Ana. Entretanto, a relação de Alain com Ana deteriora-se e ele conversa com seus pais a respeito da gravidez da ex-parceira.

No período que Alain vive no sul do Brasil, ele retoma o contato com uma antiga conhecida que vivia na região metropolitana de Porto Príncipe. Desse contato, surge a possibilidade de se casarem. O pai dela, futuro sogro de Alain, viaja para o Brasil, para acertar pormenores entre as famílias dos noivos. No sul do Brasil, o pai da noiva de Alain vive com a família de 
Alain, o que resulta em um conflito entre os familiares de Alain, evangélicos, e o pai da noiva, praticante do vodou. Manifestamente, Alain diz que sai de casa para evitar que sua família expulsasse o futuro sogro, frustrando seus planos de casamento. Com isso, Alain desaparece da cidade onde vivia com seus familiares, sem comunicar a ninguém sobre sua decisão. Mesmo com o desaparecimento de Alain, seus pais expulsam o pai da noiva de sua casa. 0 futuro sogro de Alain desloca-se para o interior de Santa Catarina, onde falece em circunstâncias pouco esclarecidas por Alain. Após um período vagando pelo Brasil, Alain retorna para a casa de seus pais, no sul do Brasil, decisão que parece ter sido influenciada por Ana, mãe de seu filho e que continuava em contato com a família de Alain, a despeito de seu desaparecimento. Nesse momento da vida de Alain, aconteceu o segundo encontro com ele, para a entrevista de acompanhamento. Ele manifestou a intenção de se reunir com sua ex-parceira brasileira e seu filho, o que não aconteceu.

Após um período no sul do Brasil e com o equacionamento de uma série de conflitos familiares, Alain mudou-se para os Estados Unidos. Novamente, desempenhou o mesmo papel em relação a sua família, qual seja, o de sair primeiro para, em um segundo momento, receber outros familiares. Após um período no sul dos Estados Unidos, onde viveu com seus irmãos (um homem e duas mulheres), seu cunhado e seu sobrinho, Alain deslocouse para o Canadá. Seus pais e seu irmão mais novo ainda vivem no sul do Brasil. Todos planejam se reencontrar no Haiti.

Os traços definidores desse tipo estão relacionados ao fato de que o imigrante que deixa o país antes de sua família para, em um segundo momento, levar seus familiares, atravessa por diversos países, como Equador, Peru, Brasil, Estados Unidos e Canadá. A decisão inicial de sair de seu país de nascimento parece es- tar fortemente atrelada à presença de um tio e de um primo maternos vivendo no Equador. O conflito advindo da chegada do resto de sua família a esse país coloca em movimento um novo processo de deslocamento, que inclui o trânsito por países como Peru, Brasil, Estados Unidos e Canadá. Ao que tudo indica, esse processo de deslocamento só cessará quando o imigrante que toma a frente do processo de saída retornar para seu país natal e conseguir levar seus familiares de volta a esse país. Nesse sentido, há a iminência de um retorno ao país natal, apesar desse retorno não se efetivar, mesmo quando há possibilidade para isso.

\section{O caso Abdou: Brasil como destino final}

O Senegal, país localizado na costa oeste do continente africano, tem uma população estimada em 12 milhões de habitantes. Com uma história milenar, sofreu grandes transformações sociais e culturais no período colonial. A independência da França foi oficializada em 1960, com a eleição do senegalês Léopold Sédar Senghor como presidente. O país tem uma grande variedade de grupos étnicos, muitos dos quais mantiveram sua cultura tradicional transmitida oralmente entre as gerações. Entre os grupos étnicos mais representativos, estão: $44,5 \%$ Wolof e Lébou (um subgrupo do Wolof), 25,2\% Pular, 13,8\% Serer, 5\% Diola, 3,9\% Mandinga e Sossé, 1,6\% Soninké e 6\% de outros grupos, incluindo estrangeiros (FALL, 2010, p. 13).

Na perspectiva religiosa, a população autodeclara-se majoritariamente mulçumana (94\%). Considerado um país de emigração, a estimativa das Nações Unidas, em 2005, indicava que em torno de 500 mil senegaleses residiam no exterior. 0 governo senegalês indica que ocorreu a migração de cerca de 2 milhões de nacionais, desde a década de 1960, princi- 
palmente em direção a países europeus e para os Estados Unidos. Recentemente, o destino tradicional de imigração dos senegaleses vem sofrendo uma crescente diversificação. Dados do censo demográfico de 2013 já indicavam países do Oriente e da Ásia como destinos diferenciados. Nesse contexto, situa-se o recente fluxo migratório do Senegal para a América Latina e para o Brasil. O Alto Comissariado das Nações Unidas para Refugiados (ACNUR) indica que, no período de 2010 a março de 2016, 7.200 senegaleses solicitaram refúgio no Brasil. Parte dos imigrantes fixou-se, inicialmente, em cidades médias, bem como em cidades pequenas, onde há a presença de grandes empresas que atuam no setor de produção e exportação de alimentos.

A migração de senegaleses para o Brasil tem suscitado pesquisas em diversas áreas, resultando em uma diversidade de produções acadêmicas que exploram diferentes perspectivas desse fenômeno. Brignol e Costa (2016) analisaram o uso da internet pelas comunidades senegalesas, no Rio Grande do Sul, segundo o conceito de "webdiáspora". ${ }^{8}$ Herédia (2015) apresentou uma perspectiva interdisciplinar sobre a migração de senegaleses para o Rio Grande do Sul. Outros estudos abordam, sob diferentes perspectivas, os impactos e os desafios postos por este fluxo imigratório. Uebel (2015) apontou as rotas empreendidas pelos imigrantes do Senegal até o Rio Grande do Sul, sua distribuição espacial no Estado e suas

8 De acordo com Brignol (2016, p. 96): “O conceito de webdiáspora está relacionado com a criação de ambientes comunicacionais marcados pela lógica do deslocamento e pela vivência em rede da própria diáspora. Incluem-se aí: múltiplos ambientes de comunicação na internet criados, mantidos, atualizados, usados por migrantes que passam a se apropriar da facilidade de acesso à esfera da produção na internet para seus próprios objetivos e demandas. Como webdiaspóricos são incluídos tanto páginas web, sites temáticos sobre migrações, quanto weblogs, sites pessoais, sites de ONGs e associações, perfis e páginas em redes sociais online, atravessados por questões relacionadas às vivências identitárias a partir de fluxos migratórios contemporâneos". relações com o mercado de trabalho, variando de acordo com as regiões nas quais se estabeleceram. Tedesco; De Mello (2015) analisou o papel centralizador do campo religioso no cenário da imigração senegalesa, ${ }^{9}$ evidenciando que o referido horizonte se compõe com as dimensões econômicas e estrutura um vínculo transnacional (em redes) de ritualidades, concepções e importância.

Abdou nasceu na região rural de Kaolak (Senegal/África), em uma família tradicional, da etnia wolof. Kaolack está localizada a sudeste de Dakar, capital senegalesa, no caminho para o Mali e a Gâmbia. A população do departamento de Kaolack é estimada em 382.700 pessoas. A região é etnicamente diversa; enquanto dominada pelo grupo wolof, também inclui outros grupos étnicos como os serer $\mathrm{e}$ os pulaar. A principal língua falada é o wolof.

As principais atividades econômicas que ocorrem em Kaolack são agricultura de base e incluem o cultivo do amendoim e do milho. 0 cultivo sazonal é feito predominantemente de modo manual, empregando mão de obra local e também imigrante (Guiné, Mali, Gâmbia). A família segue os preceitos da religião islâmica, orientação religiosa majoritária do país onde a poligamia ${ }^{10}$ é aceita sendo que sua mãe foi

9 Tedesco; De Mello (2015, p. 23) coloca que a religião “se correlaciona com a emigração e com a sua identidade de imigrante nos espaços de origem; ela é fundamental para toda a organização da vida em espaços múltiplos e transnacionalizados; cristaliza as obrigações familiares, o sentimento de pertença, a vivência em grupo e demanda espaços e momentos de ritualização. Na realidade, mesclada aos fatores econômicos (ganhar dinheiro, enviá-lo à família e melhorar a vida material), a religião torna-se o centro das intencionalidades que envolvem a imigração senegalesa para o mundo; é uma totalidade em ação e que se renova e reproduz com as condições objetivas e subjetivas que o processo migratório atual apresenta".

10 N'diaye (2017, p. 95) afirma que no "CF (código da família) de 1972, a lei islâmica é concebida como uma simples referência ao islã em um ambiente legal secular. Seu conteúdo foi definido a partir de práticas e não de um modelo suposto, uma vez que o termo se refere ao costume uolofe islamizado, definido pelo legislador como uma adaptação do Maliquismo Fiqh para os costumes do grupo étnico maioritário. Depois de ter identificado os costumes, o legislador considerou que 
a segunda esposa de seu pai, e Abdou o filho único dessa relação. A família trabalhava no cultivo do amendoim, já em decadência nos anos de 1980, e na criação de animais. Na divisão do trabalho, o cultivo da terra e o trato dos animais era destinado aos homens, enquanto às mulheres competiam as atividades domésticas. Aos três anos de idade, Abdou ficou órfão de pai, mas esse fato não the foi contado. Após um curto período prescrito no cânone religioso, sua mãe casou-se novamente, indo morar em outra cidade e deixando Abdou sob os cuidados dos avós e de um irmão dela.

As dinâmicas mobilizadas pelas alianças por casamento são bastante complexas no Senegal. Envolvem, além dos preceitos religiosos, a observância das tradições do grupo étnico, as estratégias de solidariedade baseadas no parentesco, bem como as normas legais que passaram a reger as uniões matrimoniais após o período de independência do país. No caso de Abdou, embora este tenha enfatizado, em sua narrativa, a observância do código religioso, principalmente no relato sobre o tempo que a mãe teve de aguardar para se casar novamente, não ficam claros os motivos que levaram sua mãe a não permanecer com a família do marido, após sua morte, como esperado. Nesta passagem da narrativa, fica evidente que, além do peso das dinâmicas religiosas, também emergem as dinâmicas de subsistência de ambas as famílias. Abdou objeta que não ficou com a família do pai porque não havia nenhuma pessoa que pudesse cuidar dele. Ao mesmo tempo, fica claro que estava colocada a questão do direito de herança sobre a terra do pai.

$\mathrm{Na}$ reconstrução do caso, fica claro que $\mathrm{Ab}$ dou não recebeu a herança a que teria direito,

o islamismo era o menor denominador com base no qual foi possivel elaborar a legislação familiar aplicável a todos os senegaleses. É por isso que o Ministro da Justiça teve que precisar que, na prática, o que é chamado de lei muçulmana é uma amalgamação da lei alcorânica e do direito consuetudinário". o que poderia indicar que os pais de Abdou não estivessem casados legalmente, excluindo - o dos diretos de partilha, ou ainda que a mãe tenha recusado, após a viuvez, uma possível união com um cunhado, prática comum nesses casos. De fato, a família da mãe de Abdou adota a estratégia de estabelecer uma nova aliança por casamento, restando Abdou aos cuidados dos avós, a ponto dele reconhecer que, no seu vilarejo, a maioria das pessoas pensa que ele é filho de seu avô. Bénard da Costa (2005), ao analisar as dinâmicas das uniões conjugais em Moçambique, chama a atenção para a circulação entre redes de solidariedade. Segundo a autora,

existe sempre a possibilidade de 'circulação' entre redes de solidariedade e por isso é possível aos indivíduos e às famílias estabelecerem novas alianças com outras unidades sociais (novas uniões matrimoniais) e desenvolverem processos dinâmicos e versáteis de reprodução social. (BÉNARD DA COSTA, 2005, p. 206)

No mesmo período, o tio materno, que havia se tornado o responsável por Abdou, após a morte do seu pai, migrou para a Europa. Entre 1997 e 2002, os resultados do censo senegalês de 2002 já evidenciavam a centralidade dos destinos europeus (42\%), com a Itália superando a França como principal destino (SAKHO et al, 2015, p. 32). A crise econômica da década de 1980 , bem como uma crise ambiental, ambas empurraram um número significativo de senegaleses das áreas rurais da bacia do amendoim para países europeus (SAKHO et al, 2015).

O período que se seguiu à emigração do tio de Abdou foi de grandes dificuldades econômicas. Nesse período, Abdou foi inserido na escola corânica ${ }^{11}$ e descobriu sobre a morte do pai quando tinha cerca de sete anos de idade.

11 As escolas corânicas no Senegal visam a formação das crianças dentro dos princípios religiosos islâmicos. Elas podem combinar o ensino religioso e o ensino curricular formal, sendo que o mais frequente, no interior do país, é o ensino religioso restrito. Para mais, ver: André e Demonsant (2013). 
Aos 12 anos, o tio emigrado resolveu retirá-lo da escola corânica (religiosa) e matriculá-lo na escola secular (francesa). Isso gerou um pequeno conflito intrafamiliar e na comunidade onde a família vivia. Abdou relata que foi o tio, a partir da experiência que ele fez como emigrado na Europa, que o colocou a estudar na "escola francesa", mantida pelo Estado com forte orientação laica e influenciada pelo modelo de ensino francês.

Eu fui estudar corânica até que eu tem doze anos meu tio que foi viaja no italiano que volta e diz que eles me bota na escola francês. Porque ele diz que não adianta ficar sem estudar francês ou uma coisa porque escola corânica ficou só no Senegal, só no. é uma coisa só de religião, mas se tu quer viajar tem que entender francês ou outro língua ele me bota pra estudar na escola francesa e meu vô não queria que eu entre que eu fui na escola francês e tava brabo ele não queria que eu fui estudar francês. Eu fui estudar francês até que eu terminar meu meu curso de primeiro eu fui no secundario. Eu tava estudando bem e eu eu pouco inteligente, eu estudo bem, eu nunca reprova, eu nunca voltar atrás, sempre eu passo à frente sempre, sempre. (ABDOU, 2015, trecho de entrevista)

O entrevistado constituiu dois mundos: um primeiro vinculado à tradição e à religião, aos códigos de sobrevivência internos à cultura em que vive, internos ao país onde nasceu. Um segundo mundo, externo a esse sistema: o mundo dos emigrados. Esses dois mundos são construídos pelo viés da experiência do tio, que acumula dois tipos de autoridade: aquela de tutor, responsável pela formação de Abdou, conhecedor das regras tradicionais e religiosas da sua cultura; e aquela autoridade do emigrado, de alguém que negociou seu lugar em outro sistema cultural, que conheceu e aprendeu como sobreviver fora do próprio país, confrontando outra cultura. Há o mundo da "escola corânica" que, de acordo com essa perspectiva, se restringe aos limites da vida no Senegal e não serve como código de tradução social fora desses limites. Há o mundo da escola francesa, que se abre como um código de mobilidade no contexto externo. Já na escolha definida pelo tio de Abdou de inseri-lo no sistema de ensino francês desenhava-se um projeto migratório para seu futuro. Um emigrado precisa não somente conhecer os códigos e posturas religiosos e culturais do país onde nasceu, mas também precisa aprender os códigos, a linguagem e "uma coisa" (conforme expressão do entrevistado) do outro sistema, para conseguir obter sucesso no seu projeto fora dos muros da tradição e das fronteiras geográficas do país. Abdou orgulha-se de ter conseguido apreender esses dois códigos que o qualificaram para interpor um percurso migratório para outros país: “[...] eu tava estudando bem e eu eu pouco inteligente, eu estudo bem, eu nunca reprova, eu nunca voltar atrás, sempre eu passo a frente sempre, sempre".

Antes de completar o segundo ciclo de estudos, Abdou evadiu da escola e passou a ajudar o avô em tempo integral na pequena propriedade rural da família. 0 índice de evasão escolar no Senegal, principalmente no meio rural, é alto. As vilas do interior apresentam menos estrutura e muitos jovens abandonam o estudo, logo após o primeiro ciclo de ensino. Em 2013, de acordo com dados do censo demográfico realizado pelo governo do Senegal, o índice de pessoas que nunca havia frequentado a escola na região de origem do entrevistado era de $31,5 \%$ de homens e $43,8 \%$ de mulheres. Grande parte da pressão pelo abandono da escola, no meio rural, resulta da necessidade de subsistência da família, seja para agregar mão de obra, seja para migrar para centros urbanos maiores ou para o exterior, na esperança de exercer uma função melhor remunerada.

Aos 20 anos de idade, Abdou migrou para a capital, Dakar, onde, após uma série de dificuldades, conseguiu gradativamente se estabelecer como comerciante. Prosperou a ponto de 
contratar pessoas para trabalhar com ele, em seu estabelecimento, e comprou animais, que foram colocados sob os cuidados da família do avô, que permaneceu na atividade rural. Em 2013, Abdou recebeu uma proposta de migrar para o Brasil. Apesar de estar bem colocado e da posição contrária de sua família à saída do Senegal, Abdou migrou, tendo em mente sua vontade de prosperar no Brasil.

$\mathrm{Na}$, na Dakar eu consegui trabalho bem, trabalha bem no meu loja e um dia eu fui encontra uma persona que me conta as coisas de brasileiro. Que diz que Brasil tá bem. Que os salários sao muito altos. Eu fico loco. Eu não consegui. Eu fui na cidade para conversar de novo com minha mãe que diz que eu queria sair do Senegal pra ir no Brasil. Minha mãe disse no, tem que ficar ali. Que tu tava bem agora, tu tem que ficar aqui, tu tem que arrumar mulher. Tu tem que ficar ali. Eu diz no. Eu quero mais. Eu quero ir. Ehh. A gente me conto Brasil. Eu tem acha que o Brasil é muito, muito, muito melhor. Eu vendi metade de meu vaca, os coisas, eu fui encontra uma pessoa que diz que vai levar Brasil com vista. (ABDOU, 2015, trecho de entrevista)

De acordo com Sakho et al (2015), nos fluxos imigratórios da chamada bacia do amendoim no Senegal, região de onde proveio o entrevistado:

[...] vão interagir a crise ambiental, o declínio econômico e as políticas restritivas de destinos tradicionais, e um culto baseado no trabalho e na religião. Os locais de partida e os destinos constituem, portanto, territórios descontínuos construídos em torno de redes de sensibilização comunitários. Das famílias rurais, as zonas de partida passam para as cidades costeiras, lugares ao mesmo tempo de rupturas ligadas ao progresso na educação e na abertura ao estilo de vida ocidental, mas de permanências simbolizadas pela sobrevivência de representações e valores socioculturais tradicionais. Confrontado com uma crise econômica que afeta todos os setores da produção e categorias socioprofissionais e agravamento dos controles nas fronteiras, os candidatos para a migração se multiplicam e as redes e rotas se diversificam. (SAKHO et al, 2015, p. 43)

Abdou vendeu seu estabelecimento para empregar o dinheiro no projeto migratório para o Brasil. Importante destacar que o processo migratório de Abdou se insere no contexto de imigração senegalesa para o Brasil, iniciado em 2008. Esse fluxo migratório compreende um fenômeno novo de migração Sul-Sul. Abdou passou por muitas dificuldades no trajeto, atravessando de modo irregular a fronteira do Brasil com o Peru, pela divisa do Estado do Acre. Depois de dois meses no acampamento, migrou para o Rio Grande do Sul com amigos que tinham conhecidos residindo em Passo Fundo (RS). Foi acolhido por uma entidade religiosa de apoio a imigrantes e, por intermédio da associação de imigrantes senegaleses, conseguiu uma colocação laboral numa olaria no interior Rio Grande do Sul. Após um ano e meio trabaIhando nessa empresa, sofreu um acidente de trabalho que, por negligência de atendimento, evolui para uma lesão incapacitante. Atualmente, Abdou vive no Sul do Brasil, onde aguarda o resultado da ação judicial sobre o seu caso.

As relações transnacionais, os vínculos familiares que as expressam produzem novos rituais e são produzidos por outras estratégias (estar aqui e estar lá, não estar nem aqui nem lá, ou estar aqui, mas pensando em estar lá), que ligam espaços e tempos. É por isso que as migrações se ligam a horizontes amplos e dinâmicos; envolvem renovação, alteração de hábitos, provocam crises, implicam separações e rupturas de um equilíbrio existente; denotam perdas, ganhos, aberturas e fechamentos, encontros e realizações de múltiplos fatores no campo pessoal, do lugar de destino, de oportunidades, que thes são dadas e conquistadas, das famílias e sua ampliação em afetividades e obrigações. (HEREDIA; TEDESCO, 2015, p. 142)

Nas reconstruções de caso apresentadas, evidencia-se o papel que o núcleo familiar desempenha no processo de acoplamento simul- 
tâneo a mais de uma sociedade. No caso de Alain, as relações estabelecidas por ele no Brasil, como, por exemplo, com a parceira brasileira, são diretamente negociadas com a família, assim como no caso de Abdou, cuja decisão de demandar judicialmente a reparação pelo acidente de trabalho passou pelo aval de sua família (tio, irmãos e mãe), que permanecem no Senegal. Inicialmente, a família de Abdou mostrou-se contrária à judicialização do acidente de trabalho, sugerindo que ele retornasse ao Senegal. Posteriormente, ao compreender que ele estava com uma sequela de saúde grave, a família aceitou sua decisão de permanecer no Brasil até completar o tratamento e terminar o processo jurídico. Observa-se, no caso de Abdou, a necessidade explícita que ele tem de harmonizar sua decisão de permanecer no Brasil, após o acidente, com o desejo da família em relação ao seu retorno ao Senegal.

Ao enfatizar a compreensão do fenômeno migratório, em termos processuais, a abordagem transnacional não foca apenas na sociedade de origem ou de destino do migrante. Ela leva em consideração a miscigenação de elementos específicos de consciência e de compreensão da vida daqueles que vivenciam as múltiplas localidades (APITZSCH; SIOUTI, 2007).

A dinamicidade e a amplitude dos horizontes descritos nas biografias de Alain e Abdou, em boa parte, são caracterizadas por um movimento de integração e construção de múltiplas redes, nas quais o trânsito pressupõe esse movimento de "estar aqui e estar lá". Familiares e amigos emigrados, amigos e conacionais com afinidades religiosas ou de pertença étnica são mobilizados no processo de "estar imigrante". Cada nova etapa do processo migratório e as decisões sobre permanecer ou não em determinado local, estão, ambas, envolvidas no sentimento de estar em uma condição nas quais as rupturas, perdas e ganhos, a condição de "estar cá e pensar lá" integra o universo de possibilidades em relação ao futuro, mesmo que no horizonte ainda permaneça latente um projeto de retorno ao ponto de origem.

No caso de Abdou, o projeto de retorno estava condicionado, inicialmente, à recuperação do retorno financeiro que ele empenhou ao migrar para o Brasil:

Eu, eu, eu, quando eu chegou aqui eu não queria nada, só voltar, mas eu diz que eu gastar quinze mil real, não adianta volta ligero. Eu tem que trabalha mais tempo pra, pros, pra... "junta" ajunta esses dinhero, depois volta. (ABDOU, 2015, trecho de entrevista)

Após o acidente de trabalho, o retorno ficou condicionado à questão da saúde. 0 retorno é pensado em uma perspectiva idealizada na qual o restabelecimento da saúde o colocaria em condições de voltar ao ponto de origem, ou seja, quando, com seu trabalho, conseguir acumular os bens que tinha antes de decidir migrar para o Brasil.

[...] cuando eu disse que [...] se eu volta no Senegal sem dinheiro, eu to intero, Eu pode trabalha no roça. Mas agora com uma braço, solo, uma só braço não pode trabalha. Mas eu sabe bem trabalho no roça, eu tem inteleginte pra trabalho no roça. E [...] se eu volta, amanhã, no Senegal, com saúde bom, sem dinhero, não tem problema. Eu pode trabalha um anos, eu pode fica mesmo antes que eu saí de lá. Mas agora eu preocupado, quando eu chego lá [...] a gente [...] como eles vão te pega [...] tu chego sem dinheiro [...] tu chego [...] é dificil. (ABDOU, 2015, trecho de entrevista)

No caso de Alain, a dimensão do retorno é essencial ao entendimento da trajetória desempenhada, daí a importância de compreender esse deslocamento não como pontos separados de partida e chegada, mas em sua dimensão processual. Uma perspectiva total do processo é o que confere sentido ao deslocamento, ato próprio que o migrante faz ao narrar seu passado e suas expectativas futuras, a partir do presente. Nesse sentido, remete-se 
a uma "antropologia total do ato de emigrar e de imigrar", na qual o retorno estabelece "relações com o tempo, o tempo de ontem e o tempo do futuro, a representação de um e a projeção do outro" como o "tempo cotidiano da imigração presente", em Sayad (2000, p. 11-12).

\section{Considerações Finais}

Alain e Abdou colocam em movimento a construção de relações sociais que conectam o Brasil e seus países de origem, bem como outros países onde possuem familiares e amigos emigrados. Eles mantêm essas relações nos diferentes espaços e lugares, deslocando essas interações para além dos limites geográficos nos quais se encontram circunscritos. Sem esgotar as possibilidades de análise desse fenômeno a partir da pesquisa narrativa e interpretativa, pretendeu-se indicar, pelos casos empíricos apresentados, contribuições da abordagem biográfica ao tema da migração transnacional.

A compreensão da noção de que os eventos vivenciados ao longo da trajetória de um migrante - o cruzamento de diversas fronteiras, por exemplo - está inscrita em sua biografia. Isso é, pela análise detida da estrutura pela qual um migrante narra no presente suas vivências passadas por diversas figurações sociais distintas (ELIAS, 1994), é possível ter acesso ao espaço social transnacional registrado em sua biografia, que foi forjada no deslocamento espacial por diversos pontos do globo. Mais que isso, a abordagem biográfica dá acesso à forma como o sujeito interpreta suas ações cotidianas e como negocia e planeja sua ação em relação aos outros na vida em sociedade.

A construção de mobilidades transnacionais não ocorre a um só tempo ou no momento de chegada em outro país, mas, como fica evidente, nas reconstruções biográficas, se trata de um processo configurado ao longo das histórias de vida de cada indivíduo e em relação aos grupos e sociedades dos quais provém. Es- sas reconstruções informam os pesquisadores sobre fatores latentes e manifestos presentes nas histórias de vida apresentadas pelos migrantes sobre seu deslocamento, indo além de descrições superficiais em um nível manifesto de análise. Daí decorre a necessidade de compreender essas histórias, em dois niveis distintos de análise, o da história de vida como vivenciada e o da história de vida como narrada.

\section{Referências}

ANDRÉ, Pierre; DEMONSANT, Jean-Luc. Koranic schools in Senegal: a real barrier to formal education? Paris: Agence Française de Developpement (AFD), 2013. Disponivel em: <https://mpra.ub.unimuenchen.de/53997/1/MPRA_paper_53997.pdf>. Acesso em: 04 fev. 2018.

APITZSCH, Ursula; SIOUTI, Irini. Biographical analysis as an interdisciplinary research perspective in the field of migration studies. York, 2007. Disponivel em: <https://www.york.ac.uk/res/researchintegration/Integrative_Research_Methods/Apitzsch\%20 Biographical\%20Analysis\%20April\%202007.pdf>. Acesso em: 16 fev. 2018.

BAPTISTA, José Renato. Sè Tou Melanje: uma etnografia sobre o universo social do vodu haitiano. 2012. 326 f. Tese (Doutorado em Antropologia Social) - Museu Nacional, Universidade Federal do Rio de Janeiro, Rio de Janeiro, 2012.

BÉNARD DA COSTA, Ana. Género e poder nas famílias da periferia de Maputo. Lusotopie - Recherches politiques internationales sur les espaces issus de l'histoire et de la colonisation portugaises, n. XII (12), p. 203-216, 2005.

BERGER, Peter; LUCKMANN, Thomas. The social construction of reality. London: Penguin, 1991.

BRIGNOL, Liliane; COSTA Nathália. Migração e usos sociais do facebook: uma aproximação à webdiáspora senegalesa no Rio Grande do Sul. Revista Interdisciplinar da Mobilidade Humana, v. 24, n. 46, p. 91-108, 2016.

BRODWIN, Paul. Pentecostalism in translation: religion and the production of community in the Hai- 
tian diaspora. American Ethnologist, v. 30, n. 1, p. 85-101, 2003.

CARRERA, Gabriela. Por qué migrar? Algunos apuntes sobre las viejas y nuevas heridas de Haití. Cuadernos Migratorios, La migración haitiana hacia Brasil: características, oportunidades y desafios, Organización Internacional para las Migraciones, n. 6, p. 33-50, 2014.

CÉ SANGALLI, Lucas. 0 desaparecimento de Alain: movimento e pertencimento na vida de um migrante. 2015. 93 f. Dissertação (Mestrado em Ciências Sociais) - Programa de Pós-Graduação em Ciências Sociais, Pontifícia Universidade Católica do Rio Grande do Sul, Porto Alegre, 2015.

COGO, Denise. Comunicação e migrações transnacionais - o Brasil (re)significado em redes migratórias haitianas. REU, São Paulo, v. 40, n. 2, p. 233-257, 2014.

COGO, Denise; BADET, Maria. Guia das migrações transnacionais e diversidade cultural para comunicadores - Migrantes no Brasil. Bellaterra: Institut de la Comunicación, UAB; São Leopoldo, RS: Instituto Humanitas, Unisinos, 2013.

CUNHA, Jorge Luiz da; ALHEIT, Peter. Biographieforschung in Brasilien. In: LUTZ, Helma et al. (Orgs.). Handbuch Biographieforschung. Frankfurt: Springer VS, 2018. p. 789-797.

DALMASO, Flávia. A magia em Jacmel: uma leitura crítica sobre o vodu haitiano à luz de uma experiência etnográfica. 2009. 108 f. Dissertação (Mestrado em Antropologia Social) - Museu Nacional, Universidade Federal do Rio de Janeiro, Rio de Janeiro, 2009.

ELIAS, Norbert. A sociedade dos indivíduos. Tradução de Vera Ribeiro. Rio de Janeiro: Zahar, 1994.

FALL, Papa Demba; CARRETERO, María Hernández; SARR, Mame Yassine. Senegal. Country and Research Areas Report. EUMAGINE Project Paper, v. 2, p. 10, 2010.

FERNANDES, Duval; CASTRO, Maria da Consolação. Estudos sobre a migração haitiana ao Brasil e diálogo bilateral (Relatório de pesquisa). Belo Horizonte: Conselho Nacional de Imigração e Organização Internacional para Migração, 2014.
FERNANDES, Duval; MILESI, Rosita; PIMENTA, Bruna. Migração dos haitianos para o Brasil. Cadernos de Debates, Refúgio, migrações e cidadania, Brasília, Instituto Migrações e Direitos Humanos, v. 8, n. 8. p. 55-71, 2013. Disponivel em: <http://www.migrante.org.br/index.php/component/booklibrary/1180/ view/53/Publica\%C3\%A7\%C3\%B5es/30/cadernode-debates-08-refugio-migracoes-e-cidadania>. Acesso em: 15 fev. 2018.

GLASER, Barney; STRAUSS, Anselm. The discovery of grounded theory. New Brunswick: AldineTransaction, 1967.

GLICK SCHILLER, Nina; BASCH, Linda; BLANC, Cristina Szanton. From immigrant to transmigrant: theorizing transnational migration. Anthropological Quarterly, v. 68, n. 1, p. 48-63, 1995.

GODOY, Gabriel. O caso dos haitianos no Brasil e a via de proteção humanitária complementar. In: CARVALHO RAMOS, A. et al. (Eds.). 60 anos de ACNUR: perspectivas de futuro. São Paulo: Editora CLA Cultural, 2011. p. 45-68.

GURWITSCH, Aron. Das Bewusstseinsfeld. Berlin/ New York: De Gruyter, 1974.

HERÉDIA, Vania Beatriz Merlotti. Migrações internacionais: o caso dos senegaleses no Sul do Brasil. Caxias do Sul, RS: Quatrilho Editorial, 2015.

HERÉDIA; Vania Beatriz Merlotti; TEDESCO, João Carlos Tedesco. O lugar do imigrante nos espaços de trabalho em Caxias do Sul: o caso dos senegaleses. In: HERÉDIA, Vânia Beatriz Merlotti. Migrações internacionais: o caso dos senegaleses no Sul do Brasil. Caxias do Sul, RS: Quatrilho Editorial, 2015. p. 137-168.

HOFFMANN-RIEM, Christa. Die Sozialforschung einer interpretativen Soziologie. Der datengewinn. Kölner Zeitschrift für Soziologie und Sozialpsychologie, ano 2, n. 32, p. 339-372, 1980.

LACOMBA, Joan. Immigrés sénégalais, islam et confréries à Valence (Espagne). Revue européenne des migrations internationales, v. 16, n. 3, p. 85-103, 2000.

LINSTROTH, J. P.; HALL, Alison; DOUGE-PROSPER, 
Mamyrah; HILLER, Patrick. Conflicting ambivalence of Haitian identity-making in South Florida. Forum: Qualitative Social Research, v. 10, n. 3, 2009. Disponivel em: <http://www.qualitative-research.net/ index.php/fqs/article/view/1362/2855>. Acesso em: 16 fev. 2018.

MILESI, Rosita. Haitianos no Brasil - Dados estatísticos, informações e uma recomendação. Brasília, DF: Instituto Migrações e Direitos Humanos, 2016. Disponivel em: <http://www.migrante.org.br/images/Haitianos_dados\%20PF_CNIg\%20-\%20Recomendao\%20de\%20Registro\%201.pdf>. Acesso em: 04 fev. 2018.

MORAES, Isaias Albertin de; ANDRADE, Carlos Alberto; MATTOS, Beatriz. A imigração haitiana para o Brasil: causas e desafios. Revista Conjuntura Austral, Porto Alegre, v. 4, n. 20, p. 95-114, 2013.

NEIBURG, Federico. Questionando o social - Foucault em chave etnográfica: o governo dos guèto de Porto Príncipe. Análise Social, v. 212, n. 3, p. 742-747, 2014.

N'DIAYE, Marième. A legitimação pelo direito? Os desafios do governo da família num contexto muçulmano. Uma comparação Senegal-Marrocos. Revista NEP - Núcleo de Estudos Paranaenses da UFPR, v. 3, n. 4, p. 91-111, 2017.

OEVERMANN, Ulrich; ALLERT, Tilman; KONAU, Elisabeth; KRAMBECK, Jürgen. Die Methodologie einer objektiven Hermeneutik und ihre allgemeine forschungslogische Bedeutung in den Sozialwissenschaften. In: SOEFFNER, H.-G. (Ed.). Interpretative Verfahren in den Sozial- und Textwissenschaften. Stuttgart: Metzler, 1979. p. 352-434.

PATARRA, Neide. O Brasil: país de imigração? e-Metropolis - revista eletrônica, n. 9, p. 6-18, 2012. Disponivel em: <http://emetropolis.net/edicao/n09>. Acesso em: 15 fev. 2018.

PIMENTEL, Maria Lima; COTINGUIBA, Geraldo Castro. Wout, rakète, fwontyè, anpil mizè: reflexões sobre os limites da alteridade em relação à imigração haitiana para o Brasil. Universitas Relações Internacionais, Brasília, v. 12, n. 1, p. 73-86, 2014.

PRIES, Ludger. The approach of transnational social spaces: responding to new configurations of the social and the spatial. In: PRIES, L. (Ed.). New transnational social spaces - International migration and transnational companies in the early twenty-first century. London: Routledge, 2000. p. 3-33.

REDIN, Giuliana; BARBOSA, Juliana. Da segurança internacional à segurança humana: implicações do instituto jurídico do refúgio e o caso da política externa bilateral Brasil-Haiti na questão imigratório. Boletim Meridiano 47, v. 15, n. 141, p. 10-17, 2014. Disponível em: <http://periodicos.unb.br/index.php/ MED/issue/view/871>. Acesso em: 15 fev. 2018.

RICCIO, Bruno. Toubab e vu cumprà: transnazionalità e rappresentazioni nelle migrazioni senegalesi in Italia. Padova: Cleup, 2007.

RIEMANN, Gerhard; SCHÜTZE, Fritz. Trajectory as a basic theoretical concept for analyzing suffering and disorderly social processes. In: MAINES, D. (Ed.). Social organization and social processes: essays in honor of Anselm Strauss. New York: de Gruyter, 1991. p. 333-357.

ROSENTHAL, Gabriele. National identity or multicultural autobiography? The narrative study of lives $\mathbf{5}$, p. 21-39, 1997. Disponível em: <https://www.ssoar. info/ssoar/bitstream/handle/document/5684/ ssoar-tnsl-1997-rosenthal-national_identity_or_ multicultural_autobiography.pdf?sequence=1>. Acesso em: 15 fev. 2018.

ROSENTHAL, Gabriele. A plea for a more interpretive, more empirical and more historical sociology. In: KALEKIN-FISHMAN, Devorah; DENIS, Ann. (Eds.). The shape of sociology in the 21st Century: tradition and renewal. Thousand Oaks, CA: Sage Publications, 2012. p. 202-217.

ROSENTHAL, Gabriele. Pesquisa social interpretativa: uma introdução. Porto Alegre: Edipucrs, 2014.

ROSENTHAL, Gabriele. História de vida vivenciada e história de vida narrada. Porto Alegre: Edipucrs, 2017.

ROSENTHAL, Gabriele; KÖTTIG, Michaela. Migration and questions of belonging. In: Forum Qualitative Social Research, v. 10, n. 3, Art. 19, sep. 2009. Disponível em: <http://www.qualitative-research.net/index. 
php/fqs/article/view/1372>. Acesso em: 16 fev. 2018.

SAKHO, Pape; DIOP, Rosalie; MBOUP, Bara; DIADIOU, Diodio. A emigração internacional senegalesa: das casas no campo às cidades litorâneas. In: HERÉDIA, Vania. (Org.). Migrações internacionais: o caso dos senegaleses no Sul do Brasil. Caxias do Sul, RS: Quatrilho Editorial, 2015. p. 23-48.

SANTOS, Hermílio; OLIVEIRA, Patrícia; SUSIN, Priscila. Narrativas e pesquisa biográfica na sociologia brasileira. Revisão e perspectivas. Civitas - Revista de Ciências Sociais, v. 14, n. 2, p. 359-382, 2014.

SANTOS, Milton. Por uma outra globalização. Rio de Janeiro: BestBolso, 2011.

SAYAD, Abdelmalek. O retorno: elemento constitutivo da condição do imigrante. Travessia: revista do migrante, ano XIII, número especial, p. 7-32, jan. 2000.

SCHÜTZ, Alfred. The stranger. In: SCHÜTZ, A. Collected papers II - Studies in social theory. The Hague: Martinus Nijhoff, 1964. p. 91-105.

SCHÜTZE, Fritz. Biographieforschung und narratives Interview. Neue Praxis, v. 13, n. 3, p. 283-293, 1983.

SCHÜTZE, Fritz. Biography analysis on the empirical base of autobiographical narratives: how to analyze autobiographical interviews - Part I. In: INVITE - Biographical counselling in rehabilitative vocational training: Further education curriculum 1, Module B.2.1., 2007a. Disponivel em: <http:/ / www.zsm.ovgu. de/zsm_media/Das+Zentrum/Forschungsprojekte/ INVITE/B2_1-p-140.pdf>. Acesso em: 26 jan. 2018.

SCHÜTZE, Fritz. Biography analysis on the empirical base of autobiographical narratives: how to analyze autobiographical interviews - Part II. In: INVITE - Biographical counselling in rehabilitative vocational training: Further education curriculum 1 , Module B.2.1., 2007b. Disponivel em: <http://www.uni-magdeburg.de/zsm/projekt/biographical/1/B2.2.pdf>. Acesso em: 26 jan. 2018.

SILVA, Felipe. Construções do "fracasso" haitiano. 2010. 173 f. Dissertação (Mestrado em Antropologia Social) - Programa de Pós-Graduação em Antropologia Social, Museu Nacional, Universidade Federal do Rio de Janeiro, Rio de Janeiro, 2010.

SILVA, Paloma. Seguindo rotas: reflexões para uma etnografia da imigração haitiana no Brasil a partir do contexto de entrada pela tríplice fronteira norte. 2014. 157 f. Dissertação (Mestrado em Antropologia) - Programa de Pós-Graduação em Antropologia, Universidade Federal de Brasília, Brasília, 2014.

SILVA, Sidney. Brazil, a new Eldorado for immigrants?: the case of Haitians and the Brazilian immigration policy. Urbanities, v. 3, n. 2, p. 3-18, 2013.

STEPICK, Alex. Pride against prejudice: Haitians in the United States. Boston: Allyn and Bacon, 1998.

TEDESCO, João Carlos; DE MELLO, Pedro. Imigração e transnacionalismo religioso. Os senegaleses e a confraria Muride no centro-norte do Rio Grande do Sul. Revista do Núcleo de Estudos de Religião e Sociedade (NURES), n. 30, p. 1-26, 2015. Disponivel em: <https://revistas.pucsp.br/index.php/nures/article/viewFile/27479/19441>. Acesso em: 16 fev. 2018.

UEBEL, Roberto Rodolfo Georg. Panorama e perfil da imigração senegalesa no Rio Grande do Sul no início do século XXI. Boletim Geográfico do Rio Grande do Sul, n. 28, p. 56-77, 2016.

VÁSQUEZ, Tania; BUSSE, Erika; IZAGUIRRE, Lorena. La migración haitiana en Perú y su trânsito hacia Brasil. Cuadernos Migratorios, La migración haitiana hacia Brasil: características, oportunidades y desafios, Organización Internacional para las Migraciones, n. 6, p. 83-104, 2014.

WILSON, Thomas. Theorien der Interaktion und Modelle soziologischer Erklärung. In: GRUPO DE TRABALHO DE BIELEFELD. (Orgs.). Alltagswissen, Interaktion und gesellschaftliche Wirklichkeit. Wiesbaden: VS Verlag für Sozialwissenschaften, 1980. p. 54-79.

ZAMBERLAN, Jurandir; CORSO, Giovanni; BOCCHI, Lauro; CIMADON, João Marcos. Os novos rostos da imigração no Brasil - Haitianos no Rio Grande do Sul. Porto Alegre: Solidus, 2014.

Recebido em: 15.11.2017

Aprovado em: 22.02.2018 
Maria do Carmo dos Santos Gonçalves é doutoranda do Programa de Pós-Graduação em Ciências Sociais da Pontifícia Universidade Católica do Rio Grande do Sul (PPGCS/PUCRS).

e-mail:maria.carmo1975@gmail.com

Rua Professor Marcos Martini, 1600, Caxias do Sul, Rio Grande do Sul, Brasil. Telefone: +55 54981351707

Lucas Cé Sangalli é doutorando em Ciências Sociais da Universidade de Göttingen e pesquisador do Centro de Métodos em Ciências Sociais (Métodos Qualitativos) da mesma universidade. Mestre em Ciências Sociais pela Pontificia Universidade Católica do Rio Grande do Sul (PUCRS). e-mail: lucas.sangalli@sowi.uni-goettingen.de

Goßlerstraße 19, Raum 2.102, Göttingen, 37073, Alemanha. Telefone: +49 (0)551/39-21532 